
1. 14 -
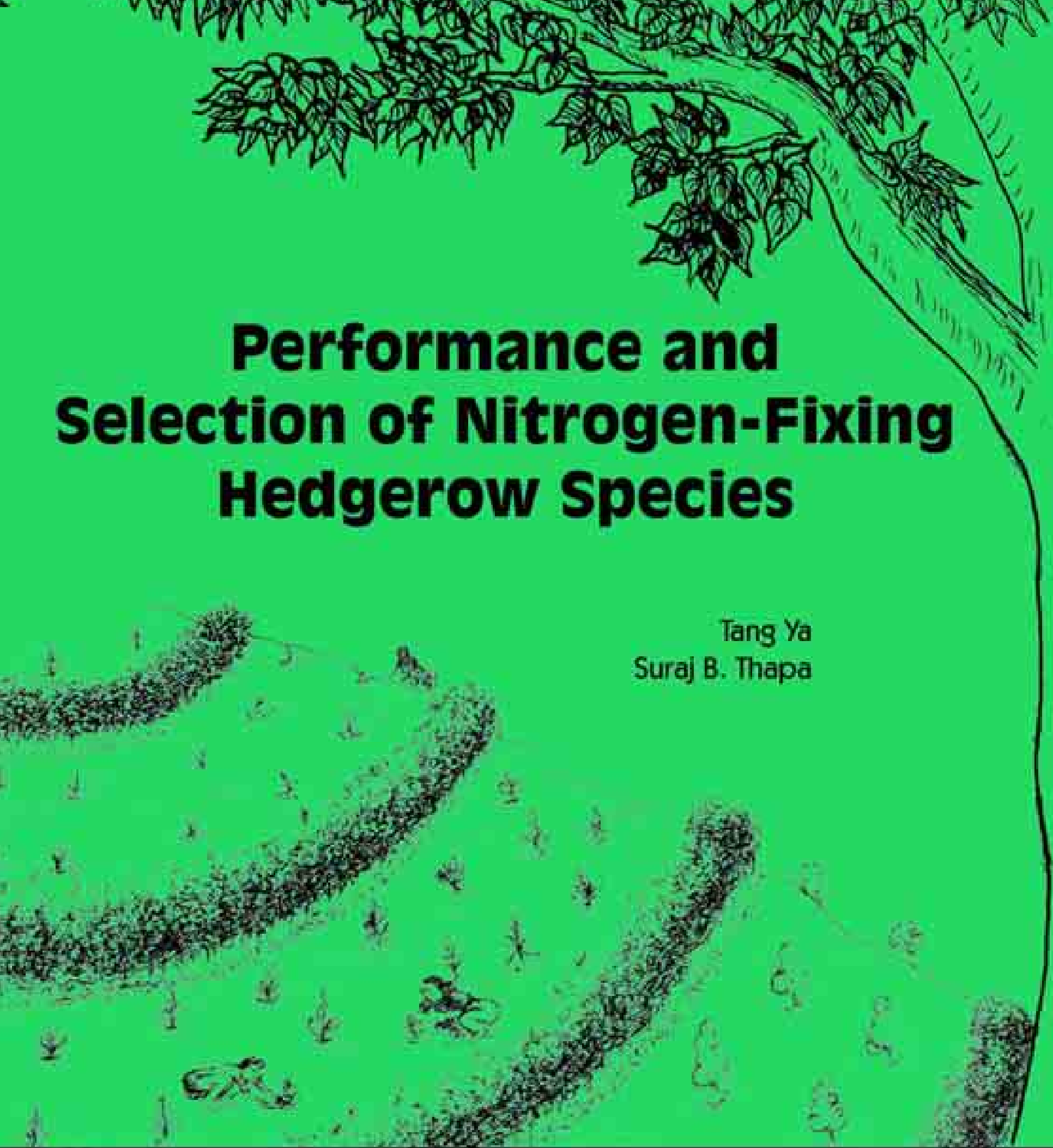

\title{
(1) Godavari
}




\section{About ICIMOD}

The International Centre for Integrated Mountain Development (ICIMOD) is an independent 'Mountain Learning and Knowledge Centre' serving the eight countries of the Hindu Kush-Himalayas - Afghanistan 2 , Bangladesh *, Bhutan

China India Myanmar Nepal \$, and Pakistan $\mathrm{C}$ - and the global mountain community. Founded in 1983, ICIMOD is based in Kathmandu, Nepal, and brings together a partnership of regional member countries, partner institutions, and donors with a commitment for development action to secure a better future for the people and environment of the Hindu Kush-Himalayas. The primary objective of the Centre is to promote the development of an economically and environmentally sound mountain ecosystem and to improve the living standards of mountain populations.

\section{Focus on Godavari}

The series 'Focus on Godavari' will feature information on topics related to the activities of the ICIMOD Demonstration and Training Centre, Godavari. The topics will include background information about technologies, species, and general approaches for integrated mountain development; results of trials and recommendations of appropriate species and technologies; and reports on outreach and training activities both on and off site.

Available titles (December 2004)

\#1 Seeing is Believing: the ICIMOD Demonstration and Training Centre, Godavari (forthcoming)

\#2 Nature's Bounty: Nitrogen-Fixing Plants for Mountain Farmers

\#3 Impact of Contour Hedgerows: A Case Study

\#4 Performance and Selection of Nitrogen-Fixing Hedgerow Species

\#5 Perennial Cash Crops for Mountain Areas (forthcoming) 


\title{
Performance and Selection of Nitrogen-Fixing Hedgerow Species
}

\author{
Tang Ya \\ Suraj B. Thapa
}

Focus on Godavari \#4

International Centre for Integrated Mounain Development

Natural Resources Management Programme

Kathmandu, Nepal

November 2004 


\section{Copyright (c) 2004}

International Centre for Integrated Mountain Development All rights reserved

\section{Credits}

Frontispiece photo by A. Beatrice Murray

Sketches by Asha Kaji Thaku

Cover design concept Sanjay Madnani

\section{Published by}

International Centre for Integrated Mountain Development

G.P.O. Box 3226

Kathmandu, Nepal

\section{ISBN 9291159271}

\section{Editorial Team}

A.Beatrice Murray (Editor)

Dharma R. Maharjan (Technical Support and Layout Design)

\section{Printed and bound in Nepal by}

Quality Printers Pvt. Ltd., Kathmandu, Nepal

The views and interpretations in this paper are those of the contributor(s). They are not attributable to the International Centre for Integrated Mountain Development (ICIMOD) and do not imply the expression of any opinion concerning the legal status of any country, territory, city or area of its authorities, or concerning the delimitation of its frontiers or boundaries, or the endorsement of any product. 


\section{Forew ord \\ Focus on Godavari}

The International Centre for Integrated Mountain Development (ICIMOD) was established in 1983 amidst increasing concern about environmental degradation and poverty in the Hindu Kush-Himalayan $(\mathrm{HKH})$ region. Its area of mandate is the Hindu Kush-Himalayan region (all or part of the eight countries Afghanistan, Bangladesh, Bhutan, China, India, Myanmar, Nepal, and Pakistan). ICIMOD's activities focus on the reduction of poverty and the conservation of the natural resource base.

The HKH sustains a population of about 150 million peoples of diverse cultures, the great majority of whom depend upon agriculture as their main source of livelihood. The well-being of mountain peoples is to a great extent determined by the state of mountain agriculture and the potential for economic improvement. Equally, the security of the livelihoods of future generations depends on ensuring that use of natural resources is sustainable, and that the environment is maintained and not degraded.

Mountain agriculture in the $\mathrm{HKH}$ is slowly transforming from traditional farming of cereal crops to mixed farming of high-value cash crops and animal husbandry for income. This agricultural transformation poses new challenges, and farmers can no longer rely solely on the wealth of indigenous knowledge acquired over generations. New choices of appropriate crops for the specific local mountain conditions, choices of appropriate methods for land use intensification without upsetting the sensitive balance of fragile mountain ecosystems, new methods of extending agricultural practices to marginal lands that stabilise rather than destroy, increasing the water supply through water harvesting and irrigation, new ways of improving crop productivity and quality without negatively affecting the environment, are technologies that must be tried, tested and integrated within existing farming systems. Many improved technologies have been developed for and promoted in mountain areas with the aim of reducing poverty and conserving the environment. But as mountain farmers have very limited resources, they are risk adverse and will not invest in an improved technology unless they can assess it carefully first. For technologies to be adopted by farmers they must first be tested and demonstrated in an accessible and convincing way.

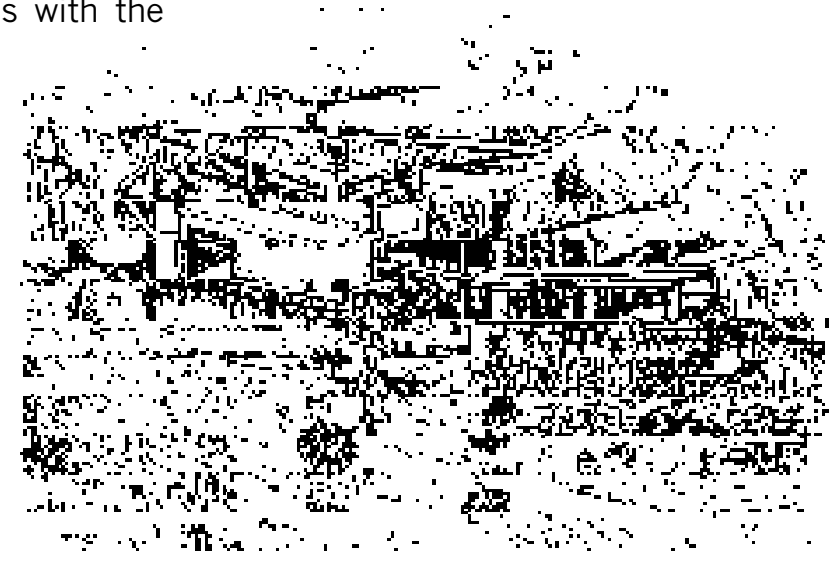


ICIMOD established its Demonstration and Training Centre at Godavari, on the southern slopes of the Kathmandu Valley, in March 1993, following the generous provision of 35 hectares of land by His Majesty's Government of Nepal in November 1992. The site provides a place where different technologies and (farming) practices useful for sustainable development can be tested, selected, and demonstrated; where farmers and those who work with them can be trained; and which can serve as a repository for plant germplasm resources and associated floral and faunal biodiversity. Activities in an integrated agricultural system are by their nature cross-cutting and often interactive and interdependent. The activities at the Godavari Centre are linked within a holistic approach that covers a broad range of the possibilities for livelihood - and quality of life improvement of mountain farmers.

Over the years a large amount of information has been accumulated related to the activities at the Godavari Centre. It includes background information about technologies, species, and general approaches for integrated mountain development; results of trials and recommendations of appropriate species and technologies; training materials; and many others. The series Focus on Godavari' has been developed to provide a platform for formal publication and wider dissemination of this information. We hope that these books will prove useful to a wide audience, and help provide information that will benefit mountain farmers. We welcome feedback from our readers and new ideas for the series.

J. Gabriel Campbell

Director General, ICIMOD 


\section{Preface}

Severe soil erosion and declining soil fertility are widely regarded as major problems threatening the sustainable use of sloping agricultural land in the Hindu Kush-Himalayan region. Sloping agricultural land technology (SALT), also known as contour hedgerow intercropping (agroforestry) technology (CHIAT), is a technique that when successful simultaneously reduces soil erosion and improves soil fertility. In this system, dense hedgerows of fast growing perennial woody tree or shrub species, usually nitrogen-fixing species, are planted along contour lines to create a living barrier that traps sediments and gradually transforms the sloping land to terraced land.

Selection of appropriate species for the hedgerows is a key factor for the successful establishment of a contour hedgerow intercropping system. Nitrogenfixing plants are recommended for most areas because they can grow in very poor soil, they grow fast, and they produce high quality fodder, as well as directly contributing to improving soil fertility in the alleys. Until now, however, most research on alley cropping or contour hedgerow intercropping has focused on a limited number of species, and most species selection studies have been aimed at tropical areas with only a few studies in subtropical areas.

The goal of species selection for a hedgerow system is to put the right species in the right place. An experiment was carried out at ICIMOD's Demonstration and Training Site at Godavari from 1993 to 2001 to test different nitrogen-fixing species and select plants suitable for establishing contour hedgerow systems in the HKH region in areas with similar agro-ecological conditions. The results of the tests for screening and selection of appropriate nitrogen-fixing plants and other multipurpose plant species are described in detail in the present publication.

Of the 24 species tested, five were finally recommended for use as hedgerow species in the Himalayan mid-hills. Many originally promising species proved to be unsuitable in the long-term, showing again how important it is to carry out proper trials over an extended period. Four of the five recommended species are local species, and the fifth a locally adapted species, indicating the need to test as many local species as possible in other regions in the future.

I hope this book will prove useful for farmers and development workers considering using SALT to slow degradation and increase the productivity of sloping land, and also provide an incentive for the increased application of this approach in the $\mathrm{HKH}$ region.

Eklabya Sharma Programme Manager Integrated Programme on Natural Resource Management 


\section{Executive Summary}

Contour hedgerow intercropping technology, or sloping agricultural land technology, has been promoted as a tool to facilitate sustainable management of sloping agricultural land. The key factor for successful application of this technology is the selection of appropriate nitrogen-fixing plant species to establish the hedgerows. Past investigations and trials have focused on tropical areas and a limited number of species. Extension of the technology to subtropical and temperate areas brings with it the need to screen other species for their potential as hedgerow species in these cooler climates; most of the hedgerow species currently used in tropical regions cannot grow in areas with low temperature.

An experiment was carried out at ICIMOD's Demonstration and Training Centre to test, select, and demonstrate various nitrogen-fixing trees and shrubs with the main objective of selecting appropriate species to establish hedgerows in the middle hills of Nepal and other areas of the HKH with similar climatic conditions. The trials started in 1993 and the bulk of the results were obtained in the ensuing seven years. A total of 21 nitrogen-fixing plant species from various origins (plus three of the same species from different origins) were tested. They were assessed for nursery germination rate, seed weight, mortality rate, height growth, base girth growth, branching characteristics, and biomass production. The germination rate in the nursery varied from 3 to $98 \%$; there was no direct relationship between seed weight and germination rate. Twelve species that showed good germination and emergence at the plant nursery were planted as hedgerows. The remaining species were excluded from the trial as a result of very poor germination or very poor growth or for other reasons; a few of the excluded species were planted separately as non-hedgerow plants to test whether they would in fact grow.

Of the 12 species used to plant hedgerows, five died completely during the trials, five almost died, and five survived: Alnus nepalensis, Flemingia macrophylla, Albizia lebbeck, Indigofera dosua, and Desmodium floribundum. The average mortality rates over all sites and years were fairly similar for the five surviving species, ranging from $31.4 \%$ for Albizia lebbeck to $39.6 \%$ for Indigofera dosua. All the five species that survived the trials are indigenous species, although the Flemingia macrophylla seeds

were obtained from the Philippines. After initial failure, a further hedgerow of Leucaena leucocephala was planted to reassess suitability; it has survived and performed satisfactorily but was not included in the detailed trials. This species is an introduced but already domesticated species. All the directly introduced species failed. Alnus nepalensis had the highest growth rate and biomass production and Desmodium floribundum the lowest.

Five species are recommended as hedgerow species for Godavari and other areas with similar climate and soils on the basis of selection criteria related to habit (tree, shrub, herbaceous), growth rate, coppicing capacity, ability to fix nitrogen, suitability to local conditions, ease of reproduction, and rooting character; these are, in order 
of recommendation, Flemingia macrophylla, Leucaena leucocephala, Indigofera dosua, Alnus nepalensis, and Albizia lebbeck. Most of the species used to establish hedgerows in tropical areas, including Calliandra calothyrsus, Cassia siamea, Desmodium rensonii, and Gliricida sepium, are not suited to the mid hills climate. Although Alnus nepalensis was the species used to establish most hedgerows at Godavari, it is not recommended for use if there are other species available because of the high cost of establishing hedgerows and its susceptibility to insect herbivores. Testing of further species suitable for cooler climates is needed. 


\section{Acknowledgements}

The authors would like to thank Mr. Jivan Tamang for the collection of the field data. The Governments of China, Nepal, and Pakistan generously provided most of the trees, shrubs, and other plants tested at the Demonstration and Training Centre. The financial support from various donors, especially the Asian Development Bank, for most of the research and activities carried out at the site is gratefully acknowledged.

\section{Acronyms and Abbreviations}

ADB Asian Development Bank

ATSCFS Appropriate Technologies for Soil Conserving Farming Systems

ICIMOD International Centre for Integrated Mountain Development

CHIAT contour hedgerow intercropping agroforestry technology

$\mathrm{HKH} \quad$ Hindu Kush-Himalayas

SALT sloping agricultural land technology 


\section{Contents}

Foreword - Focus on Godavari

Preface

Executive Summary

Acknowledgements

Acronyms and Abbreviations

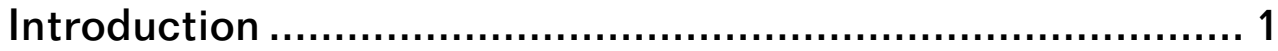

Materials and Methods ........................................... 2

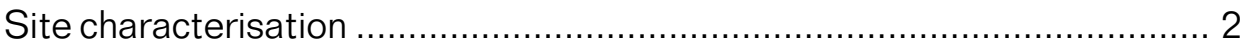

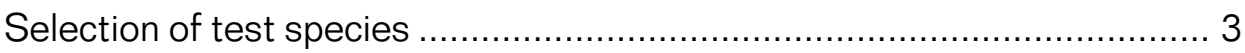

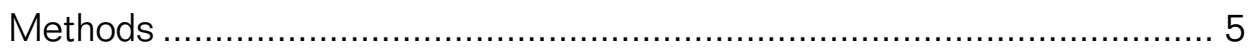

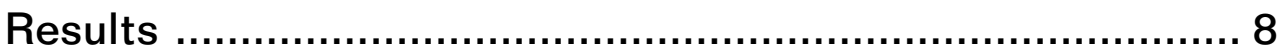

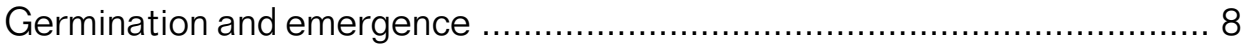

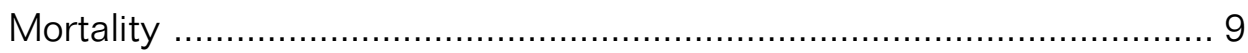

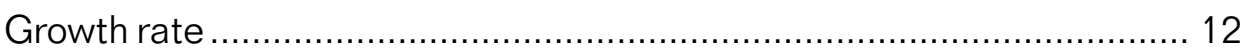

Discussion .......................................................... 17

Important criteria for species selection for hedgerows ........................ 17

Recommended species ............................................................... 19

Unsuccessful species and species meriting further testing .................... 21

Indigenous vs exotic species ....................................................... 22

Lessons and Implications for Further Work ................... 23

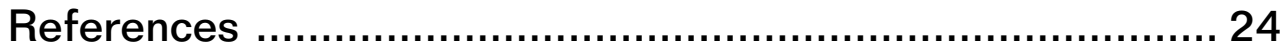

